\title{
Improved postgraduate training system needed
}

$\mathrm{C}$ anada's postgraduate medical training system is failing to meet the needs of both graduates and Canadians, delegates at the Canadian Medical Association (CMA) General Council learned during an Aug. 25 session. The 275 delegates overwhelmingly supported a motion to incorporate discussion from the session into a formal report on improving the system.

Action is essential, according to Melanie Béchard, vice president of government affairs at the Canadian Federation of Medical Students and one of two panelists discussing the system. She pointed to the increasing number of unmatched medical graduates and to how medical students don't reflect the communities and populations that require care.

Béchard cited 2014 data indicating that $8 \%$ of employment opportunities for physicians were in surgical practice, yet $16 \%$ of residents that year were in a surgical discipline. Conversely, there were 51 vacancies for geriatric specialists across the country.

One of the confounding factors is the increase in subspecialties, which may overshadow the need for generalization, said Dr. Ashley Miller, vice president of Resident Doctors of Canada and the session's second panelist. "We're advocating for a critical evaluation. I'm worried that residents who enter into subspecialities have very little versatility."

There was consensus among presenters and delegates that determining demand for physicians in subspecialties is problematic in the absence of definitive evidence or even any reliable data about job prospects. "Often the data really just doesn't exist," said Miller.

Trainees are often urged to enter a specialty instead of family practice. More than one conference participant noted that it is not unusual for medical students to be told they "are too smart for family medicine." At the same time,

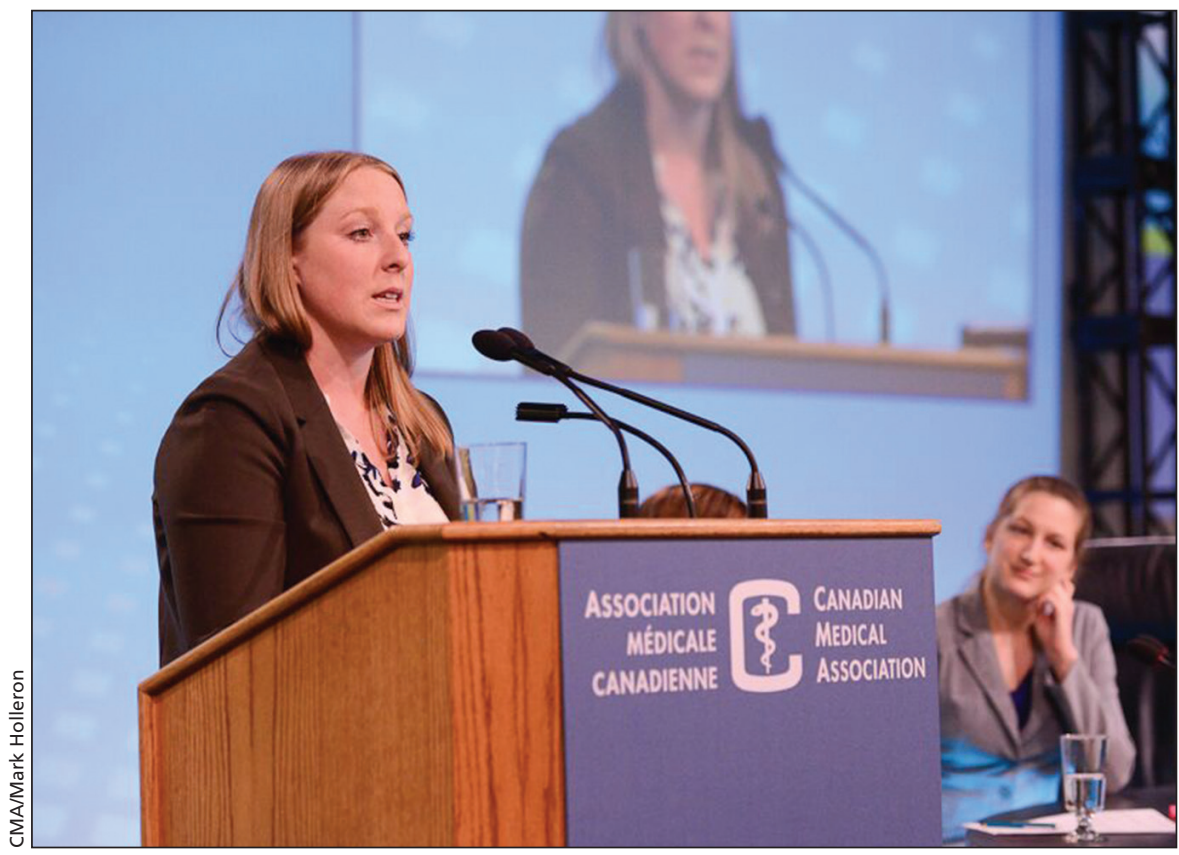

The number of unmatched medical graduates is rising, said Melanie Béchard of the Canadian Federation of Medical Students.

students are frequently encouraged to do what they love. "That is reasonable advice, but there is great variability in terms of what trainees might like to pursue," said Miller.

Career counselling — both informed and substantive - was identified as an essential part of an effective postgraduate medical system. But many medical students receive very little, said Béchard. She cited a University of Alberta study that found roughly $45 \%$ of medical graduates had not received any career counselling.

Postgraduate training must be founded on social accountability to ensure the right mix of physicians is available to meet society's needs, said Miller. "There is no ongoing surveillance about whether we're getting this right. Are we really the best people to meet the needs of our population?"'

There was also discussion about how to encourage residents to practise in the community. The panelists recommended mandatory community place- ments as part of medical training, "so students can see the unique challenges and opportunities," said Béchard.

"The reality is that many of our residents and students are located in academic centres," said Miller.

The call for a national, integrated approach to Canada's postgraduate medical training system was echoed by many of the delegates and observers who rose to speak on the issue. A nationwide system would also eliminate duplication of efforts, said Miller. "There needs to be a singular coordinated voice."

However, the voices speaking on these issues should not be confined to governments or the medical profession; the public needs to understand the landscape on which the future of their health care system is being built. "It is important to educate the public," said Béchard. "It's not just about doctors wanting jobs. It's about providing health care to Canadians." - donalee Moulton, Halifax, NS

CMAJ 2015. DOI:10.1503/cmaj.109-5140 